\title{
A New Trend of Developing the Fin-tech in Vietnam
}

\author{
Tran Van Nam - Pham Thanh Nga \\ Faculty of Law, National Economics University (NEU), Hanoi, Vietnam
}

Email address:

pham.nga.hlu@gmail.com

To cite this article:

Tran Van Nam - Pham Thanh Nga. A new trend of developing the Fin-tech in Vietnam. International Journal of Finance and Banking Research. Vol. 7, No. 3, 2021, pp. 76-81. doi: 10.11648/j.ijfbr.20210703.12

Received: November 8, 2020; Accepted: December 25, 2020; Published: August 23, 2021

\begin{abstract}
In recent year, when the $4^{\text {th }}$ industrial revolution explored around the World, digital age has opened a new trend of payment. One of its achievement is using fin-tech to develop bank and finance field. Following that trend, there are many fintech companies established in Vietnam now. The rapid increasing in the number of Vietnam start-ups operating in the financial services sector, along with a corresponding growth in investment in this sector, has attracted significant attention from observers and the media. Vietnam currently ranks second amongst ASEAN member states in the number of incubators, accelerators, and innovation labs in the region. However, Fin-tech in Vietnam is still facing with many problems, such as the lack of legal system to govern inclusive activities of fin-tech companies is example. In this paper, the author will give some statistic and information of status using Fin-tech in Vietnam. The paper will analyze the problems Vietnamese fin-tech company facing now. Then, the author will give recommendation to suggest some solutions to improve the stature of Fin-tech in the next period. To do this research, the author use many methodologies such as using data base of some organization, analysis and assessment, make survey, refer regulation and law of Vietnam, etc.
\end{abstract}

Keywords: Fin-tech, Facts, Problems, Solutions, Vietnam

\section{General Introduction}

Financial technology, often shortened to Fin-tech, is the technology and innovation that aims to compete with traditional financial methods in the delivery of financial services. [6] "Fin-tech is a new financial industry that applies technology to improve financial activities." Fin-tech is the new applications, processes, products, or business models in the financial services industry, composed of one or more complementary financial services and provided as an end-to-end process via the Internet. [15] Fin-tech can also be considered as "any innovative ideas that improve financial service processes by proposing technology solutions according to different business situations, while the ideas could also lead to new business models or even new business. It is an emerging industry that uses technology to improve activities in finance. [14] The use of smartphones for mobile banking, investing services and crypto-currency are examples of technologies aiming to make financial services more accessible to the general public. Financial technology companies consist of both Start-ups and established financial institutions and technology companies trying to replace or enhance the usage of financial services provided by existing financial companies. [12, 13]

In Vietnamese, Fin-tech just appeared and develop very quickly recent year. The market was worth $\$ 4.4$ billion in 2017 , and is predicted to reach $\$ 7.8$ billion by 2020 , equaling a $77 \%$ increase over three years. Fin-tech development in Vietnam is accelerating with companies in the sector attracting US\$117 million in start-up capital, surpassing ecommerce at US\$104 million and other sectors which makes Fin-tech the most funded sector for start-ups in 2018.

In compare with the international fin-tech around the world, global investment in financial technology increased more than $2,200 \%$ from $\$ 930$ million in 2008 to more than $\$ 22$ billion in 2015. The nascent financial technology industry in London has seen rapid growth over the last few years, according to the office of the Mayor of London. Forty percent of the City of London's workforce is employed in financial and technology services. In Europe, US\$1.5 billion was invested in financial technology companies in 2014, with London-based companies receiving US\$539 million, In the Asia Pacific region, and the growth will see a new financial technology hub to be opened in Sydney, in April 2015. According to KPMG, Sydney's financial services sector in 
2017 creates 9\% (nine per cent) of national GDP and is bigger than the financial services sector in either Hong Kong or Singapore. A financial technology innovation lab was launched in Hong Kong in 2015. In 2015, the Monetary Authority of Singapore launched an initiative named Fin-tech and Information Group to draw in start-ups from around the world. It pledged to spend US\$225 million in the Fin-tech sector over the next five years.

\section{Literature Review}

Following Mr. Nghiem Thanh Son [1], Facts and Solutions to completing legal system on Fin-tech in Vietnam, Journal of Banking, and Volume 3: Although the State has orientations in supporting innovative start-ups, including Fintech businesses. Fin-tech can be applied in many different fields, so it will be managed and under the responsibility of many different ministries and agencies. However, the laws of Vietnam have not yet specified the specific management institutions as well as the specific functions and duties of any state management agency in the Fin-tech sector and there is no coordination mechanism between the Ministries and branches in the management of Fin-tech activities are intertwined and inter-coordinated. Besides, up to now, there are no regulations on the organizational structure of the specialized division that has the function of advising leaders at all levels in the management and supervision of this activity.

By September 2019, Vietnam ranked at position of second in ASEAN, attracting 36\% of the region's fin-tech investment, only after Singapore (rate 51\%). Some organization such as PricewaterhouseCoopers (PWC), United Overseas Bank (UOB), and the Singapore Fin-tech Association supposed that Vietnam had a sharp increase in funding and attributed to two large deals going to payments companies: VNPay (US\$300 million) and MoMo (US\$500 million). [5] The two deals were the top largest and third largest funding rounds of the region. In Vietnam, investors favor payments, which is common for economies in the early stages of developing a fin-tech sector. Payments companies took $98 \%$ of total fintech funding amount in Vietnam. Vietnam's fin-tech companies, and most particularly those in the payments space is driven by the business potential in the market's large and unbanked population as well as the high mobile and Internet penetration rates.

Innovative technologies bring financial institutions and Fin-tech Start-ups closer. The spreading of these Start-ups also means that established financial institutions can look forward to a market that will increasingly be about partnerships as part of their digital banking strategy growth. In ASEAN, banks have been actively collaborating with Fintechs to drive efficiency and enhance customer experience. Most banks have an incubator, accelerator, or innovation lab which helps drive collaboration with Fin-tech firms. Some ASEAN banks have also launched Fin-tech-focused investment funds.

\section{Methodology of Research}

To make this paper, the author use the methodology of research and analysis Vietnam legal policy and documents (law and regulations) related to or govern fin-tech activities.

Besides, the author base on the hypotheses developed in the study show how to use law and regulation to govern fintech activities in Vietnam. To examine these relationships, the author developed some hypotheses and tested these hypotheses using some empirical models. The developed models confirm the assumptions and demonstrate that increasing the use of law and regulation to govern fin-tech activities. The hypotheses which are personal views regarding the relationship between independent and dependent variables based on the literature review.

Moreover, statistic and survey are also used to finish this research. The author use the poll to survey the clients who use app of fin-tech for payment when buy or sell something on the internet. The author also sent the questionnaires to the fin-tech company to ask them some question related activities of fin-tech.

The research of this paper is finished base on combining all of methodologies above. However, because of time and finance limitation, the paper-working still lack of some information. The author hope to take the opinion of audience and reviewer to do better for the next time.

\section{Findings and Discussion}

\subsection{The Fact of Using Fin-tech in Vietnam}

Following the trend of fin-tech around the World, Vietnamese people use fin-tech more day by day recent years. By 2019, there were about 136 fin-tech companies incorporated in Vietnam. According to the Fin-tech Startup Vietnam Map 2019, payment is the most advanced segment applying fin-tech, counting about 35 companies. Notable ventures and platforms include MoMo, a mobile payments platform by M_Service and one of the most well-funded fintech startups in Vietnam, Moca, a mobile payments service integrated into super-app Grab, and ZION, the company behind Zalo Pay, a service integrated into Vietnam's popular messaging platform Zalo. Vietnam's fin-tech market has been worth about US\$ 9 billion in 2020, making it ASEAN's fourth-largest market.

With 35 start-ups and platforms, payments is the most populous fin-tech segment. Notable companies and brands in this segment include M_Service, the developer of mobile payments app MoMo and one of the most well-funded fintech start-ups in Vietnam, Moca, a free mobile payment application for Vietnamese consumers, GrabPay, a mobile wallet integrated into Grab's app in Vietnam, and ZION, the company behind Zalo Pay, a service integrated with Vietnam's popular messaging platform Zalo that lets users link a payment card to make P2P payments, pay via NFC, $\mathrm{QR}$ codes, as well as purchase products and services online, mobile top-ups, and pay their utility bills. [9]

Peer-to-peer (P2P) lending is the second largest fin-tech 
segment in Vietnam with over 20 start-ups. Players and solutions in the area include Tima, a consumer financial marketplace and P2P lending platform, Growth Wealth, a P2P lending platform for small and medium-sized enterprises (SMEs) in Vietnam, as well as Trust Circle, and Vay Muon. Block-chain and crypto-currency is another area that's witnessed significant traction in the past years. Since the launch of Bit-coin Vietnam, the country's first bit-coin broker exchange, in 2014, several companies have emerged to tap into the block-chain and crypto frenzy. These include TomoChain, a public block-chain promising faster and cheaper transactions designed to support decentralized applications, and Kyber Network, an on-chain liquidity protocol that aggregates liquidity from a wide range of reserves, enabling instant and secure token exchange in decentralized applications.

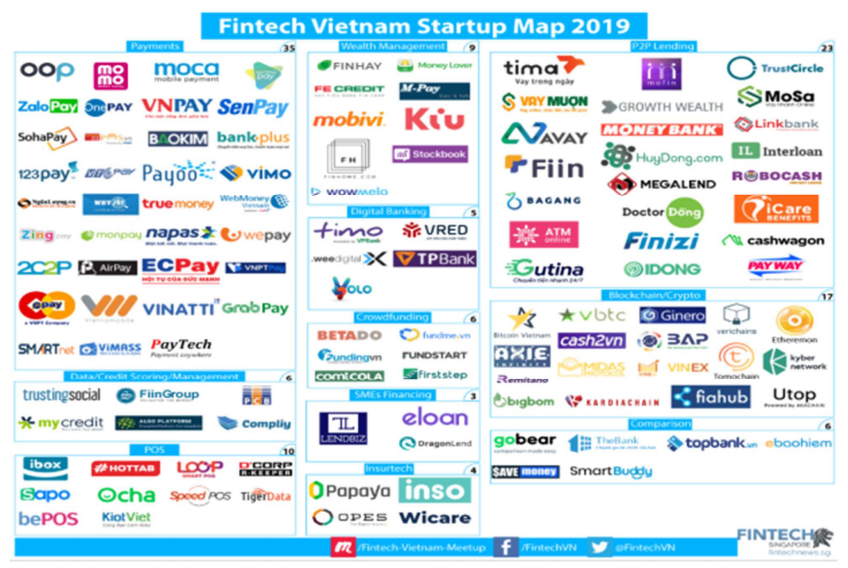

Figure 1. Image of Fin-tech Vietnam Start-up Map 2019.

About the Vietnam market of Fin-tech, only 59 per cent of Vietnam's population have a formal bank account, while the rest have no access to banking services. Due to these relatively low financial inclusion rates, Vietnam is among the 25 priority countries on which the World Bank is focusing its financial inclusion efforts through the "Universal Financial Access (UFA) by 2020" initiative, which seeks to bring two billion unbanked people into the formal financial system. Since 2016, the State Bank of Vietnam has been partnering with the World Bank on a comprehensive approach to financial inclusion, which will result in a national financial inclusion strategy towards a cashless economy. Considering this situation, we can say Fin-tech was born from the desire for change in the developing the World. With all the favorable factors - from the rapidly expanding economy and the young, urban, digital-savvy population to the increasing mobile and internet penetration. Fin-tech plays a key role in significantly improving Vietnamese people's access to financial services.

Similarly with the development of Fin-tech in the World, it is all about digital payment. We have witnessed a boom in the development of a cashless Vietnamese society in Vietnam. Major deals include the co-operation between South Korea's UTC Investment Group and VNPT Electronic Payment Company (VNPT E-pay), as part of which UTC spent
VND542 billion (US\$24 million) acquiring a 65-per-cent stake in VNPT E-pay from VMG Media and a number of individual shareholders; MOL Access Portal's acquisition of 50 per cent of Ngan Luong's shares; NTT Data's acquisition of 64 per cent of Payoo's shares; True Money buying a 40per-cent stake in 1Pay; and an investor group including Credit Saison, Golden Gate Ventures, and GMO Global Payment Fund purchasing a 25-per-cent stake in payment gateway company Bao Kim. [3]

Vietnamese Fin-tech companies are focusing on the field of payments, with 47 per cent of Vietnamese companies working on payment services, the highest rate in the region. More Fin-tech firms are born in the payment sector every day, and forecasts say the transaction value of digital payments will reach US\$12.2 billion by 2022. [2]

Since fin-tech appears in Vietnam, it opens a new age of financial services. Today, Vietnamese banks are in the first phase of their digital revolution, where most banks collaborate with Fin-tech firms to offer their customers highquality online banking websites, mobile apps, and other digital initiatives such as loan origination, front-end customer acquisition, and payment processing. These institutions started providing new and digitally differentiated ways of offering financial services to the consumer. For example, VIB co-operated with Weezi, a young, motivated Vietnamese Fin-tech Start-up, to launch an embedded social keyboard that allows their customers to transfer money and to check account balances easily on their smartphones. VietinBank announced a partnership with Opportunity Network, a leading UK Fin-tech, to create a digital small and mediumsized enterprise (SME) platform which helps their SME customers acquire funding more quickly. Similarly, TPBank recently co-operated with local Fin-tech Instant.vn on developing an SME lending platform. In the near future, banks in Vietnam will increasingly look to apply Fin-techs across their entire value chain, from front-end and back-end to enhancing customer service and driving greater productivity.

\subsection{The M\&A Activities of Fin-tech in Vietnamese}

Mergers and acquisitions (M\&A) could be the future trend for Fin-tech in Vietnam. Fin-tech is an M\&A focus for financial sponsors and an investment focus for many established financial institutions. Global financial institutions are increasingly looking to "market infrastructure" Fin-techs as a cure for internal cost management and an enabler to unlock the benefits of disruptive technology. Acquiring a Fintech firm can increase a bank's digital footprint and shortcut the development of new technology. Large global banks have been engaging in this Fin-tech approach due to its benefits, such as a rapid route into new markets, new customers at low cost, opportunities to cross-sell, product differentiation, and access to talent and innovative culture. Notable Fin-tech deals this year include TD Bank in January acquiring Layer 6, an artificial intelligence company based in Toronto that uses technology to offer personalized and predictive communications to financial services customers. JPMorgan 
Chase acquired two payment-oriented Start-ups in 2017. This aligns with the organizational goal of scaling Chase Pay, the bank's payments solution.

Despite the global trend, we have not seen many financial institutions acquiring Fin-techs in Vietnam. From a technical point of view, one the biggest challenges comes from the integration of new Fin-tech technology solutions into Vietnamese legacy banking systems. Most banking systems in Vietnam are considered to be outdated, which could lead to significant costs. According to an EY ASEAN Fin-tech census report, 59 per cent of surveyed banks have budgeted to invest 10 per cent more in technology in 2018 , and 44 per cent of them plan to buy new technology from third parties, while only 17 per cent are interested in acquiring a Fin-tech company to possess its technology.

From a management point of view, due to the heavily centralised organisational structure of Vietnamese financial institutions, acquiring a Fin-tech firm may impact the bank's organisational culture and lead to internal tension. Another factor to be considered is the lack of successful use cases, as the Fin-tech trend is a recent development in Vietnam. Facing such challenges, Vietnamese banks are choosing a conservative approach when it comes to acquiring Fin-tech firms.

Having said that, with forecasted compound annual growth rates of 31.2-35.9 per cent between 2017 and 2025, we believe that more banks will look to build their own Fin-tech products and that more Fin-tech M\&As or acquire-hires could follow in the near future. Mergers between Fin-tech firms are another possible outcome, since there are a total of 77 Fin-tech firms in Vietnam, while only half of them are active. [8]

On the other hand, the rapid growth of Vietnamese Fintech is garnering increased interest from foreign banks. Foreign investors at odds with the regulated caps on foreign ownership in banks (currently 30 per cent) may look for opportunities to collaborate with Fin-tech firms to tap into the banking sector. [7] Sources say Shinhan Bank and KEB Hana are both looking at and studying opportunities for investment in local Fin-tech firms.

Like local banks, foreign players would like to add value to their banking products and services, especially focused on the retail market, where customer experience is key. Determining the approach to Fin-tech depends on the bank's business plan and objectives - whether it is a go-to-market or product and service enhancement.

Going forward, both local and foreign banks are looking for more diversified Fin-tech products, as the current Fintech landscape in Vietnam focuses mostly on payments. P2P lending, the second-biggest Fin-tech investment sector according to a CB Insights report on Vietnamese Fin-tech, and other Fin-tech areas such as credit scoring, wealth management, and personal finance are in the development stage, with high potential to grow.

\subsection{Legal Policy and Regulation on Fin-tech in Vietnam}

Although Fin-tech is very new in Vietnam as the technology achievements of 4.0 Industry Revolution but Vietnam Government is trying to make inclusive policy and regulations to govern this field. However, the legal framework of Fin-tech in Vietnam is still infancy, just have some regulations to guild people establishing a common direction and giving principles. Accordingly, Vietnam currently has only a few macroeconomic projects for Startups in general, such as the Scheme on Supporting National Innovation and Ecosystem of Innovations until 2025 (Project 844); or broad projects such as the Project on Improving the accessibility of banking services for the economy, the Project on developing cashless payment in the period of 2016-2020, the Project on Improving the legal framework for management, dealing with all kinds of virtual assets, electronic money, virtual money... Meanwhile, the specific legal provisions for this type of "unprecedented money" business such as defining operating models, status legislation, conditions of establishment and operation, nature of products and services; standards of products / services, or regulations on the protection of consumers of financial products, the protection of personal information... have not yet been formally established. [4]

Crypto currencies like Bit-coin are another example. They are not considered a legal means of payment in Vietnam, and have not been recognized as an asset in the Vietnamese legal system. The Ministry of Industry and Trade currently does not recognize Bit-coin as a goods or service, and denies its authority over Bit-coin, which also removes the basis for tax collection. The exchange of Bit-coin still takes place but "is not protected by law", Bit-coin trading contracts are not a civil transaction under the scope of the Civil Code, if a contract dispute occurs will not be resolved by the court.

A fairly important sector in the financial industry is credit (lending). This is the district for banks and they are subject to the Law of Credit Institutions $(2010,2017)$ as well as international standards such as Basel II and III. Currently, there are many Fin-tech participating in peer-to-peer lending (P2P lending) that directly connects capital holders and those who need capital through online platforms without intermediaries such as banks. Basic peer lending is only governed by the Civil Code $(2005,2015)$ as a regular loan, but this law only outlines the general principles of personal transactions and is considered to be " not enough "to coordinate a P2P relationship. If a Fin-tech company only has the task of intermediating the responsibility, the responsibility will be settled by the two borrowers, but experts say that it will not exclude the possibility that Fintech companies will raise capital by many ways. How to lend while the legal corridor is still sketchy. This also has the potential to infringe on consumer rights and the risk of money laundering.

While Fin-tech enterprises registered in Vietnam are subject to domestic regulations, foreign companies entering Vietnam are more difficult to control and can do whatever they want. Recently, Facebook has launched an ambitious blueprint for the Libra crypto currency (expected to appear in mid-2020) that has a global scale shocking central banks of 
many countries. The delay in Vietnam's legal policies has made it difficult for domestic companies to grow in size, invisibly clear the way for foreign companies to dominate the market, or make it difficult for Vietnamese enterprises. Accumulate enough domestic experience to complete the product, reach out to foreign markets.

\subsection{Challenges to Policy Makers of Vietnam on Governing Fin-tech Field}

Fin-tech is associated with many risks such as personal security, customer protection, credit, network security, technology dependence, money laundering, etc. Therefore, the legal regulations on the one hand must be separate to create space for Fin-tech enterprises to develop, and on the other hand, the risks attached must be minimized. [10,11]

Although slower than some regional countries, Vietnam also has certain moves related to Fin-tech policy. In March 2017, the State Bank of Vietnam (SBV) established a Steering Committee for Financial Technology with the goal of perfecting the legal framework and Fin-tech ecosystem in Vietnam. The Payment Department of SBV is assigned as the Standing Committee of the Steering Committee. It is known that the SBV is focusing on researching five key issues such as block-chain technology, peer-to-peer lending (P2P Lending), electronic customer identification (e-KYC), and application program interface. Open (Open API), electronic payments (e-payments). SBV and some ministries such as Ministry of Science and Technology, Ministry of Information and Communications, Ministry of Justice... had quite a number of international seminars taking place to exchange Fin-tech experiences with countries as well as consult with enterprises.

The establishment of Vietnam's legal framework for Fintech is considered to be "cautious step by step". Experience from leading countries such as Thailand and South Korea shows that it also took them more than 2 years to go from research to policy issuance, but basically enough policies and to take advantage of a few years ago. The experimental legal framework (Regulatory Sandbox) is a promising model that is being prioritized by the SBV. This is also the pressure to ask for more than 1 year continuously from businesses and investors. The international organization's evaluation indicators show that Vietnam's policy changes are slow and many technology - related areas are considered "behind life".

One of the barriers that caused the Fin-Tech legal framework to be incomplete early was due to limited management knowledge. In addition to being well-versed in the financial field, Fin-tech's newness and technical complexity requires legal builders to understand the technology in order to see the nature of social relations regardless how the new "crust". Foreign language is also a requirement because the most complete Fin-tech documents are usually in international reports and research in English. Understanding the legal system is fundamental. In addition, Fin-tech management (and many new areas in IR. 4th) requires risk - taking thinking - something that only a part of Vietnam's public sector has started to change.
But it is undeniable that the Vietnamese legal system is gradually changing to meet the requirements of the 4th industrial revolution and the trend of international integration. The SBV supported the development of Fin-tech and said that the management direction in the coming time for this industry would change from the management based on principles of risk assessment (risk-based) to address each specific activity and situation.

Along with that, a series of fundamental legal documents of the country are being amended and supplemented. In order to accelerate the process of perfecting the mechanisms and policies for the Start-up ecosystem in general. Mr Bui The Duy, Deputy Minister of Science and Technology, urged businesses to persevere to raise their voice more firmly about problems in order to contribute to promoting the inter-branch of state agencies in supporting businesses.

As planned, in August 2018, the SBV must submit to the Prime Minister Draft documents on crypto currencies and peer-to-peer lending. The Ministry of Finance shall research, propose amendments, supplements and new legal documents on taxes on virtual assets and virtual currencies to be completed in June 2019. The Ministry of Public Security proposed measures to prevent, handle criminal violations of fraud, money laundering, terrorism financing and other crimes related to virtual assets and virtual currencies in September 2019. [6]

\section{Conclusion and Recommendation}

From the analysis above, we can see that Legal bases that grant oversight authorities sufficient (or greater, broader) powers to oversee all the participants of their NPS, including non-financial entities. The state needs to build own internal legal capacity (by adding legal specialists to mix skill) ondemand to legal expertise department.

We need to design to extend beyond systemic importance considerations, to cover systems that large enough to have potential effects on public confidence, and widely-used payment instruments. For non-designated systems, it is critical that central banks can gather and analyze the necessary information to identify cases requiring closer scrutiny - legal and capacity issues. Need to bring intermediaries (example: online payment gateways) under direct oversight, while keeping a balance between light-touch regulation on one hand, and a focused oversight including authorization on the other hand. [15]

Payment systems and services are characterized by constant innovation and changes deliberately introduced from the outside or emerging as part of the internal dynamics of the systems. Oversight authorities should be able to assess the extent of the impact of such changes, and in a position to intervene if and when necessary, possibly before they become effective. Policy dialogue is more generally used as a means to improve overall NPS policy and to align the overseer's objectives with NPS participant need to have the appropriate forum in place. 


\section{References}

[1] Nghiem Thanh Son (2020), Facts and Solutions to completing legal system on Fin-tech in Vietnam, Journal of Banking, Volume 3.

[2] World Bank, Payment system remittances, http://www.worldbank.org.

[3] Casey Hynes (2018), How Vietnam's Fin-tech Market Could Reach Nearly $\$ 8$ Billion By 2020, https://www.forbes.com.

[4] How Vietnam will adapt to the Fin-tech revolution, https://www.vir.com.vn.

[5] Vietnam News (2018), MoMo named in Fin-tech100 report, https://vietnamnews.vn.

[6] Financial technology, https://en.wikipedia.org.

[7] Phuong Linh (2018), Fin-tech co-operation - The trend of modern banking, www.sbv.gov.vn.

[8] Fin-tech News Vietnam, (2019), A Review of Vietnam's Fintech Industry in 2019, https://fin-technews.sg.

[9] Global Fin-tech Industry 2020 - 2024, Market report, https://www.reportlinker.com.

[10] The Business Research Company (2020), Fin-tech Global Market Opportunities and Strategies To 2030: COVID 19 Impact and Recovery, https://www.reportlinker.com.

[11] G. I. Khotinskay (2019), Fin Tech: Fundamental Theory And Empirical Features, Conference: GCPMED 2018 International Scientific Conference "Global Challenges and Prospects of the Modern Economic Development, DOI: 10.15405/epsbs.2019.03.23

[12] Young-mo kangKyeong HanKyeong HanSe-Jeong ParkJongBae Kim (2016), A Study on the Trends of Fin Tech, DOI: 10.14257/ijunesst.2016.9.7.07.

[13] Nicola PierriYannick TimmerYannick Timmer (2020), Tech in Fin before FinTech: Blessing or Curse for Financial Stability, DOI: $10.5089 / 9781513519258.001$.

[14] Ashwini Sanmath (2018), Fin Tech Banking - The Revolutionized Digital Banking, DOI: 10.31142/ijtsrd18699.

[15] Jing Wang (2020), The Routledge Handbook of Critical Finance Studies. 